\title{
A comparative study of adverse drug reactions reported by healthcare professionals and patients in a tertiary care teaching hospital
}

\author{
Harsha Ramakrishnaiah*, Sushma Naidu, Jyothsnya S.
}

Department of Pharmacology, The Oxford Medical College Hospital and Research centre, Bangalore, Karnataka, India

Received: 16 March 2017 Accepted: 25 March 2017

*Correspondence to: Dr. Harsha Ramakrishnaiah, Email:

harsha.ramakrishnaiah@gmail.c om

Copyright: (C) the author(s), publisher and licensee Medip Academy. This is an openaccess article distributed under the terms of the Creative Commons Attribution NonCommercial License, which permits unrestricted noncommercial use, distribution, and reproduction in any medium, provided the original work is properly cited.

\begin{abstract}
Background: Adverse drug reactions (ADRs) are one of major health concern affecting population of all ages causing significant morbidity mortality and hospitalization of the patients increasing the economic burden on the society. Monitoring of ADRs is of paramount importance for the continued effective and safe use of medicines. Though they are unavoidable accompaniments of pharmacotherapy, the reporting of ADR is poor and inadequate. Substantial under-reporting and selective reporting of ADRs are the major drawbacks of the commonly followed method of spontaneous reporting by healthcare professionals (HCP). Patient direct reporting of ADR has been incorporated into the pharmacivigilance (PV) system in several countries like USA, Canada, Australia, New Zealand, Denmark, Sweden and the Netherlands. Patient direct reporting of ADR was qualitatively similar to HCP ADR report. Patient reports often had richer narratives than those of HCPs. Patient reports often contained detailed information about the impact of the suspected ADR on the patient's quality of life. The quality of ADR reported by the patients was similar to the reports by HCP in terms of description of ADRs and its severity. So, present study was taken to evaluate the process of spontaneous reporting of suspected ADR by the patient and compare the quality of ADR reported by Health care professional and Patients.
\end{abstract}

Methods: This study was a prospective observational study conducted in 111 consecutive patients who experienced ADRs in the department of medicine Comparison between spontaneous reporting by healthcare professionals and patient direct reporting of adverse drug reactions was assessed in terms of response rate, pattern of ADR reported, causality by Naranjo s scale, severity by modified Hartwig scale and preventability by using Schumock and Thornton scale. Social, emotional, occupational impact due to ADR and narrative elaboration scores were also compared.

Results: Majority of the ADRs were from $\mathrm{HCP}$ as compared to patient reporting, indicating that better awareness among HCP about pharmacovigilance Majority of the reactions reported by patient were mild in severity, in contrast majority of ADR reported by HCP were moderate. Comparisons between HCP reporting and patient direct reporting also revealed that majority of ADR in both groups were probably preventable. Qualitative analysis reported ADR showed that majority of ADR reported by HCP had no narration or had scant narration, in contrast to patient direct reporting had very elaborate narration of ADR. Patient who did direct reporting of ADR highlighted more about emotional impact, occupational impact and social impact of ADR occurred to them, when compared to ADRs reported by HCP.

Conclusions: Patients were clearly willing to report any adverse drug reactions occurring to them. The evidence indicates that patient reporting of suspected ADRs has more Potential benefits than drawbacks. The results indicate that patient perceptions of potential ADRs are relevant and should be an integral part of ADR reporting system.

Keywords: Adverse drug reaction, Patient self-reporting 


\section{INTRODUCTION}

Adverse drug reactions (ADRs) are inevitable consequences of drug therapy, as no pharmacotherapeutic agent is completely free from noxious and unintended effects. They are major contributors for morbidity, mortality and hospitalization of the patients increasing the economic burden on the society. Though they are unavoidable accompaniments of pharmacotherapy, the reporting of ADR is poor and inadequate. ${ }^{1}$

Healthcare systems rely mainly on the detection and, assessment and spontaneous reporting of suspected ADRs by health care professional. ${ }^{2}$

Substantial under-reporting and selective reporting of ADRs are the major drawbacks of the commonly followed method of spontaneous reporting by healthcare professionals (HCP). Upto $57 \%$ of ADRs are unrecognized by attending physicians, leading to its inappropriate management. ${ }^{3}$ The various factors frequently associated to inadequate ADR reporting by HCP are poor work place environment, increased work load, and no specific training in pharmacovigilance. The influence of attitudes responsible for the failure to recognize and report a recognized ADR as proposed by Inman include complacency that only safe drugs are allowed to the market, fear of possible involvement in litigations or investigations, guilt of having caused harm to the patient, ambition to compile and publish a personal case series, ignorance of requirements of reporting, hesitancy at the prospect of appearing ridiculous for reporting merely suspected ADR, indifference of HCP to suspected ADR, lethargy due to lack of interest or time, procrastination, no financial incentives. ${ }^{4,5}$ Patient direct reporting of $\mathrm{ADR}$ has been incorporated into the pharmacovigilance (PV) system in several countries. Patient direct reporting of ADR was qualitatively similar to HCP ADR report. Nevertheless, patient reports gave detailed descriptions of suspected ADRs, recognized reactions to specific medicines and provided information useful for assessing causality. Patient reports often had richer narratives than those of HCPs and rarely provided irrelevant information or ambiguities. Patient reports often contained detailed information about the impact of the suspected ADR on the patient's life, thus providing insights that were comparatively rare in HCP reports. ${ }^{6}$ the quality of ADR reported by the patients was similar to the reports by HCP in terms of severity of the clinical problems. Literature review of patient reporting of ADRs concludes that none of the countries with patient reporting systems had identified poor quality of patient reports as an issue. ${ }^{7}$ So Patient reporting of suspected ADRs has the potential to increase knowledge about the possible harm of medicines direct and spontaneous patient reporting offers added value for pharmacovigilance in that it can speed up the acquisition of knowledge about adverse effects. Patient reports are more direct and often more detailed and explicit than indirect reports through health professionals.it supports and allows for greater patient participation. In the process the patient learns how to manage her or his medicines and to communicate more effectively with health professionals. Lastly, public health estimates of disease burden in populations do not consider the effects on people's everyday lives, and they should. For these reasons, direct patient reporting should be encouraged and routinely incorporated in pharmacovigilance activities.

\section{METHODS}

The prospective study was conducted in the wards and outpatient department of general medicine, KIMSH and RC Bangalore from Jan 2012 - June 2013, after obtaining approval and clearance from the institutional ethics committee. All patients of either gender who developed an ADR during the above-mentioned period fulfilling the inclusion were included in the study. Regular awareness and motivational programme for the patients to report any suspected ADR to our pharmacovigilance unit was conducted. They were motivated to report the suspected ADRs either verbally or through writing in a specific ADR reporting form of our institution. Comparison between spontaneous reporting by healthcare professionals and patient direct reporting of adverse drug reactions was assessed in terms of response rate, pattern of ADR reported, causality by Naranjo s scale, severity by modified Hartwig scale and preventability by using Schumock and Thornton scale. Social, emotional, occupational impact due to ADR and narrative elaboration scores were also compared.

\section{Statistics analysis}

The data were analyzed using descriptive statistics namely mean and standard deviation for quantitative variables and the association between two different discrete variables was assessed using Chi-square test.

SPSS V13 statistical software was used to generate graphs and tables wherever necessary. All multiple responses are reported in terms of percentages and total of such response will be greater than sample size. The chi-square test was implemented to analyse the association between two discrete variables, mean, and standard deviation to assess quantitative variables from the pooled data.

\section{RESULTS}

In present study ADR reporting between patient and HCP were compared in terms of pattern, causality, severity, preventability factors and impact of ADR on social, emotional and occupational life. Figure 1 will represent ADRs reported by HCPs and patients. Among 111 suspected ADRs, majority $71 \%(\mathrm{n}=79)$ were reported by HCP and 29\% ( $\mathrm{n}=32)$ were reported by patient showing the necessity for increased awareness of ADR reporting for the patient. Among the health care professional 
majority of ADRs were reported by post graduate's students. Modified Kuppuswamy scale was considered to evaluate the socioeconomic status. When compared the socioeconomic status of cases reported by HCPs and patient direct reporting. Among the ADRs identified and reported by HCPs majority (44\%) were from lower middle class, followed by upper lower class (30\%), upper middle (15\%) and upper class (10\%). Whereas among patient direct reporting of ADRs majority (47\%) were from upper socioeconomic status indicating higher awareness of ADRs among them, followed by lower middle $(28 \%)$, upper middle $(22 \%)$, upper lower $(3 \%)$.

Table 1: Comparison of presenting complaint between HCP and patient.

\begin{tabular}{|llllll|}
\hline ADR & HCP & \multicolumn{2}{c|}{ Patient } & p value \\
\hline Skin Rash & $\mathbf{n}$ & $\mathbf{0}$ & $\mathbf{n}$ & $\mathbf{\%}$ & 0.4305 \\
\hline Itching & 35 & 23 & 8 & 18 & 0.5421 \\
\hline Nausea and Vomitting & 33 & 22 & 8 & 18 & 0.1420 \\
\hline Headache & 13 & 9 & 1 & 2 & 0.4326 \\
\hline Abdominal discomfort & 2 & 1 & 0 & 0 & 0.0003 \\
\hline Diarrhoea & 2 & 1 & 6 & 13 & 0.01276 \\
\hline Constipation & 1 & 1 & 3 & 7 & 0.06719 \\
\hline Sleep Disturbances & 0 & 0 & 1 & 2 & 0.58290 \\
\hline obesity & 1 & 1 & 0 & 0 & 0.3390 \\
\hline Lab Abnormalities & 3 & 2 & 0 & 0 & 0.2151 \\
\hline Breathlessness & 5 & 3 & 0 & 0 & 0.3830 \\
\hline Giddiness & 8 & 5 & 1 & 2 & 0.4956 \\
\hline Swelling of legs & 11 & 7 & 2 & 4 & 0.8126 \\
\hline Myalgia & 8 & 4 & 2 & 4 & 0.5447 \\
\hline Tremors & 4 & 2 & 2 & 4 & 0.5447 \\
\hline Yellowish discolouration of sclera & 4 & 2 & 2 & 4 & 0.5447 \\
\hline Others & 16 & 12 & 2 & 4 & 0.3725 \\
\hline Total & $\mathbf{1 5 0}$ & $\mathbf{1 0 0}$ & $\mathbf{4 5}$ & $\mathbf{1 0 0}$ & \\
\hline
\end{tabular}

Table 1 shows the comparison of presenting complaint between patient and HCP. Among presenting complaint there was no statistically significant difference ( $\mathrm{p}$ value 0.4305) between the two groups, except for gastrointestinal side effects like abdominal discomfort, epigastric pain, diarrhoea was complained more by patients $(20 \%)$ than HCP $(2 \%)$ which was statistically significant ( $\mathrm{p}$ value 0.0003 ). Skin rashes were commonly complained by both the groups, followed by itching.

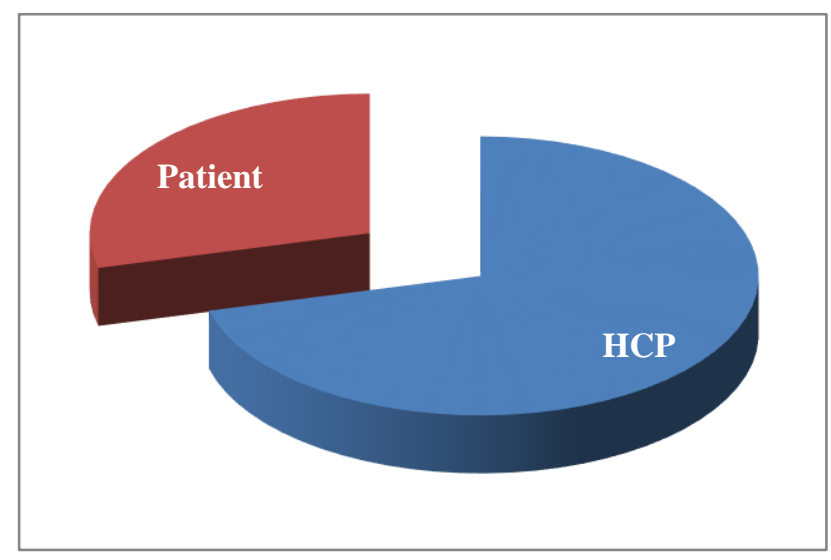

Figure 1: Number of cases reported by HCP and patient.
The suspected therapeutic class of drugs causing ADRs was elaborated in Table 2 shows comparison of suspected class of medication causing ADR between HCP and patient direct reporting elaborated in Table 2. Among HCP reported $51 \%(n=40)$ of ADR s reported were due to antimicrobials as compared to $34 \%(n=11)$ in patient reporting, followed by $13 \%$ (11) of ADRs by antiretroviral in HCP group as compared to none in patient group ( $\mathrm{p}$ value 0.03 ). There was no statistically significant difference in other class of medication causing ADRs between HCP and patient direct reporting of ADR.

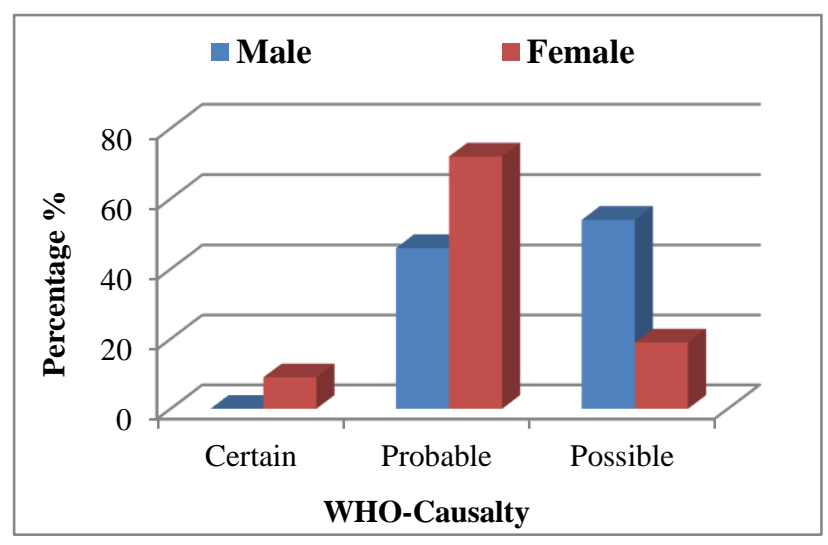

Figure 2: comparison of WHO-causality assessment of ADR reported by $\mathrm{HCP}$ and patient. 
Assessment of causality scale revealed that $46 \%$ of ADR reports by $\mathrm{HCP}$ were probable as compared to $72 \%$ of patient reporting. Fifty-four percent $(n=43))$ of HCP reports were assessed as possible while it was only $19 \%$ $(n=6)$ in patient reporting. None of the HCP ADR report could be categorized under certain causality term whereas $9 \%(n=3)$ reports of patient ADR reporting came under certain group the reason being plausible time relationship to drug intake, definitive pharmacologically recognized phenomenon with accidental re-challenge. There was a statistically significant difference in WHO-causality assessment between HCP and patient ADR reporting ( $p$ $<0.001$ ) with patient reporting more of certain and probable category (Figure 2).

Table 2: Comparison of suspected class of medication.

\begin{tabular}{|c|c|c|c|c|c|}
\hline \multirow{2}{*}{ Suspected medication } & \multicolumn{2}{|c|}{ HCP } & \multicolumn{2}{|c|}{ Patient } & \multirow[t]{2}{*}{ P value } \\
\hline & $\mathbf{n}$ & $\%$ & $\mathbf{n}$ & $\%$ & \\
\hline Antimicrobials & 40 & 51 & 11 & 34 & 0.1195 \\
\hline Anti Virals & 10 & 13 & 0 & 0 & 0.03487 \\
\hline NSAIDS and Analgesics & 4 & 5 & 4 & 13 & 0.1701 \\
\hline Antihypertensives and Diuretics & 1 & 1 & 3 & 9 & 0.03786 \\
\hline Oral Hypoglycemic Agents & 0 & 0 & 1 & 3 & 0.1145 \\
\hline Anti pileptics & 4 & 5 & 2 & 6 & 0.8022 \\
\hline Corticosteroids & 4 & 5 & 1 & 3 & 0.6556 \\
\hline Bronchodialators & 1 & 1 & 1 & 3 & 0.5048 \\
\hline Opoid Analgesics & 1 & 1 & 0 & 0 & 0.5226 \\
\hline Hypolipidemic agents & 1 & 1 & 1 & 3 & 0.5048 \\
\hline Anti-emetics & 1 & 1 & 1 & 3 & 0.5048 \\
\hline Anti-cancer agents & 2 & 2 & 0 & 0 & 0.3606 \\
\hline Anti histaminics & 1 & 1 & 1 & 3 & 0.5048 \\
\hline Anti-cholinergic & 1 & 1 & 1 & 3 & 0.5048 \\
\hline Anxiolytics & 1 & 1 & 0 & 0 & 0.5226 \\
\hline Anti-psychotic & 1 & 1 & 0 & 0 & 0.5226 \\
\hline Anti-depressant & 2 & 2 & 0 & 0 & 0.8697 \\
\hline Hematinics & 1 & 1 & 1 & 3 & 0.5048 \\
\hline Vitamin A analogue & 1 & 1 & 1 & 3 & 0.5048 \\
\hline Others (tamsulosin (1), chloroquine (1), calciumcarbonate (2) & 1 & 1 & 3 & 9 & 0.03786 \\
\hline Total & 79 & $100 \%$ & 32 & 100 & \\
\hline
\end{tabular}

Assessment of severity (Figure 3) revealed that. Majority of patient ADR reporting was mild (88\%) severity as compared to only $16 \%$ by HCP. The reason could be better perception of even a mild ADR by the patient than HCP. Among HCP reports, $78 \%$ were of moderate severity as compared to $9 \%$ by patient reporting. Figure 4 shows the comparison between HCP and patient ADR reporting using modified Schumock and Thornton preventability scale. Majority of ADRs $92 \%$ of $\mathrm{HCP}$ and $84 \%$ of patient reporting were probably preventable. Among definitely preventable group $16 \%$ were from of patient reporting as compared to $5 \%$ of $\mathrm{HCP}$ reporting. There was no statistical significant difference ( $\mathrm{p}$ value 0.128) in preventability assessment of ADRs reported by HCP and patient. Table 3 summarizes the comparison of elaboration score between ADRs reported by HCP and patient. Majority of ADRs reported by patient (50\%) were very elaborative as compared to $1 \%$ by $\mathrm{HCP} .48 \%$ of HCP reported ADR which were non-narrative as compared to none by patient reporting. Scanty narrativeness was noted in $48 \%$ of $\mathrm{HCP}$ reporting as compared to only $16 \%$ in patient ADR reporting. Moderate elaboration was seen in $34 \%$ of patient ADR reports when compared to only $3 \%$ by HCP. Elaboration score was higher in patient reported ADR than HCP ADR reports $(\mathrm{p}<0.0000001)$ highlighting that patient are more capable of recognizing and explaining an ADR than HCP. Social impact due to suspected ADR like restriction of normal routine activities due to muscle and joint pain, visual defects, confusion, depression was noted in $22 \%$ in patient reporting (Table 4), while only $9 \%$ of HCP reported ADR conveyed social impact. Majority (91\%) of HCP reporting of suspected ADR did not reveal about any social impact due to ADR. Though the social impact of ADR was more mentioned in patient ADR reporting, the difference was not statistically significant between the two groups. On comparison of occupational impact due to ADR between HCP and patient direct reporting (Table 5).

Occupational impact like unable to work due to head ache, nausea, vomiting, sleep disturbances were reported by majority $(44 \%)$ of patients as compared to only $16 \%$ by $\mathrm{HCP}$ report with statistically significant difference $(\mathrm{p}$ value 0.002 ). 


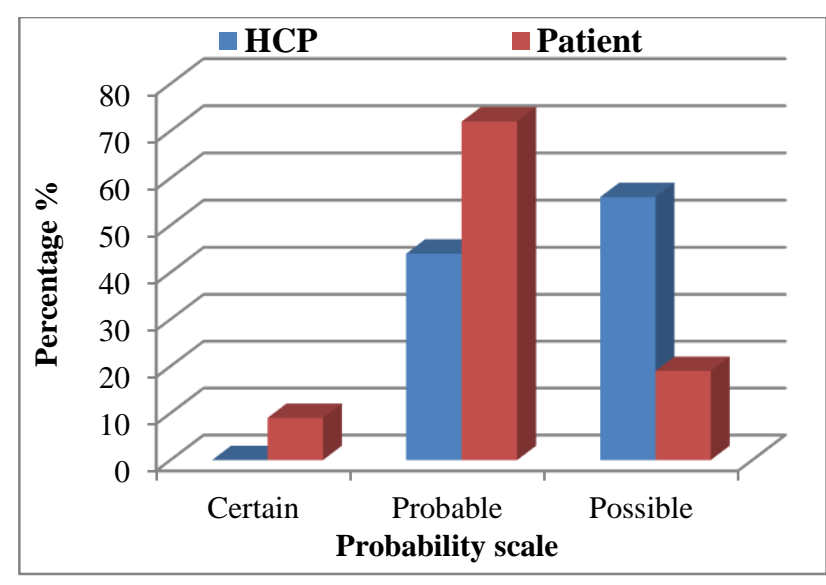

Figure 3: comparison of Naranjo s probability assessment of ADR reported by $\mathrm{HCP}$ and patient.

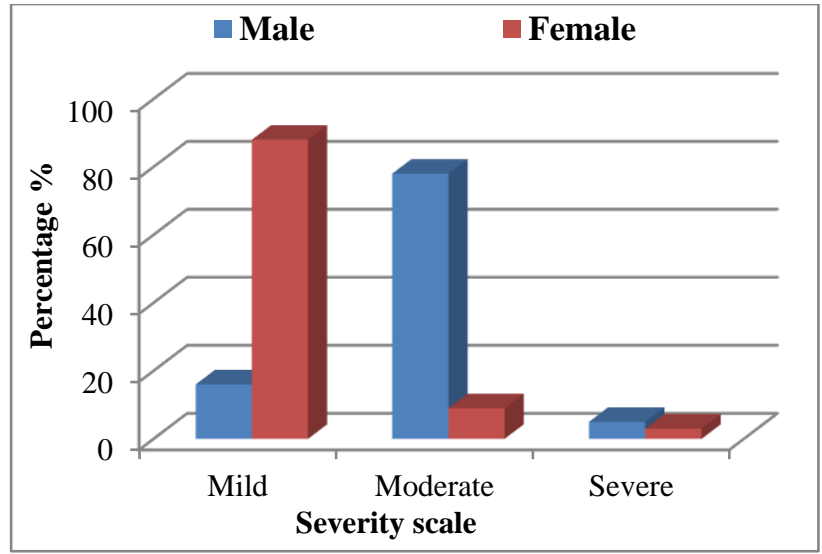

Figure 4: Comparison of severity of ADR reported by HCP and patient through modified Hartwig scale.

Table 3: Comparison of narration reported ADR between HCP and patient.

\begin{tabular}{|c|c|c|c|c|c|c|}
\hline \multirow{2}{*}{ Elaboration score } & \multicolumn{2}{|c|}{ HCP } & \multicolumn{2}{|c|}{ Patient } & \multirow[t]{2}{*}{$\chi^{2}$} & \multirow[t]{2}{*}{ p value } \\
\hline & $\mathbf{n}$ & $\%$ & $\mathbf{n}$ & $\%$ & & \\
\hline No Narrative & 38 & 48 & 0 & 0 & \multirow{5}{*}{76.63} & \multirow{5}{*}{0.0000001} \\
\hline Scant Narrative & 38 & 48 & 5 & 16 & & \\
\hline Moderately Elaborate & 2 & 3 & 11 & 34 & & \\
\hline Very Elaborate & 1 & 1 & 16 & 50 & & \\
\hline Total & 79 & 100 & 32 & 100 & & \\
\hline
\end{tabular}

Table 4: Comparison social impact due to ADR between HCP and patient.

\begin{tabular}{|c|c|c|c|c|c|c|}
\hline \multirow{2}{*}{ Social impact } & \multicolumn{2}{|c|}{ HCP } & \multicolumn{2}{|c|}{ Patient } & \multirow[t]{2}{*}{$\chi^{2}$} & \multirow[t]{2}{*}{$P$ value } \\
\hline & $\mathbf{n}$ & $\%$ & $\mathbf{n}$ & $\%$ & & \\
\hline Yes & 7 & 9 & 7 & 22 & \multirow{3}{*}{3.500} & \multirow{3}{*}{0.06138} \\
\hline No & 72 & 91 & 25 & 78 & & \\
\hline Total & 79 & 100 & 32 & 100 & & \\
\hline
\end{tabular}

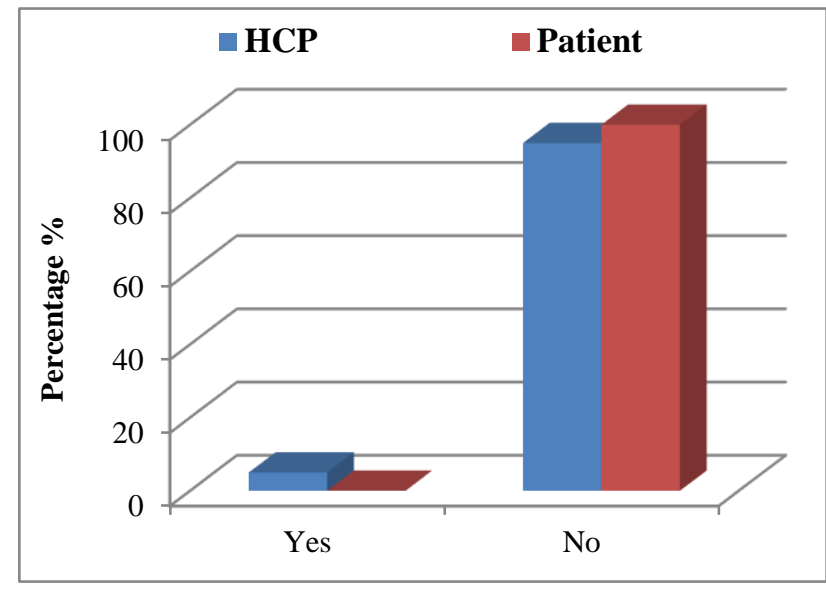

Figure 5: Comparison emotional impact of ADR reported between HCP and Patient.

Figure 5 shows the comparison of ADR between HCP and patient direct reporting on emotional impact of the reaction on the patient. Emotional impact was clearly reported by majority $(31 \%)$ of patient reporting as compared to only $13 \%$ by $\mathrm{HCP}$ report which was statistically significant ( $\mathrm{p}=0.02097)$. Emotional impact of ADR was reported with drugs like Atropine (delirium, confusion, prednisolone (depression, disturbed thoughts), ciprofloxacin, ofloxacin (anxiousness), chlordiazepoxide (low mood confusion) in patient ADR reporting.

\section{DISCUSSION}

In the present study, the mean age of the study subject was 40.77 years with male preponderance which was in conformity with previous studies. ${ }^{7,8}$ The predominant pattern of ADR noted were skin rashes with itching which is in accordance with earlier studies. ${ }^{9,10}$

The common organ system involved was skin which is in concordance with previous studies. ${ }^{11,12}$ The common causative class of drugs were antimicrobials consistent with previous studies reflecting that the antimicrobial agents are the most commonly prescribed and utilized drug. ${ }^{13,14}$ 
Table 5: Comparison of occupational impact due to ADR between HCP and Patient direct reporting.

\begin{tabular}{|c|c|c|c|c|c|c|}
\hline \multirow{2}{*}{ Occupational impact } & \multicolumn{2}{|c|}{ HCP } & \multicolumn{2}{|c|}{ Patient } & $\chi^{2}$ & p value \\
\hline & n & $\%$ & $\mathbf{n}$ & $\%$ & \multirow{4}{*}{9.217} & \multirow{4}{*}{0.002397} \\
\hline Yes & 13 & 16 & 14 & 44 & & \\
\hline No & 66 & 84 & 18 & 56 & & \\
\hline Total & 79 & 100 & 32 & 100 & & \\
\hline
\end{tabular}

A Majority of the ADRs were from HCP as compared to patient reporting, indicating that better awareness among HCP about pharmacovigilance. Majority of patient selfreporting of ADR was from upper socio economic status in contrast to HCP reported ADR containing majority of study subject from lower middle socioeconomic status. The predominant presenting complaint both in HCP and patient reported ADR were dermatological like skin rashes and itching showing that skin is one of the major target organ for ADR (ref). The commonly implicated causative class of drug in both patient and HCP reporting of ADR were antimicrobials (ref). Among antimicrobials, in HCP reporting ceftriaxone was the leading causative drug where as in patient reporting it was amoxicillin.

Similar probability pattern with both WHO-UMC causality assessment and Naranjo's probability scale was observed in both HCP and patient self-reporting indicating that ADR assessment by patients was almost similar to HCP. Majority of the reactions reported by patient were mild in severity, in contrast majority of ADR reported by $\mathrm{HCP}$ were moderate. Comparison between HCP reporting and patient direct reporting also revealed that majority of ADR in both groups was probably preventable.

Qualitative analysis reported ADR showed that majority of ADR reported by HCP had no narration or had scant narration, in contrast to patient direct reporting had very elaborate narration of ADR.

Patient who did direct reporting of ADR highlighted more about emotional impact, occupational impact and social impact of ADR occurred to them, when compared to ADRs reported by $\mathrm{HCP} .{ }^{15}$

Potential drawbacks of patient reporting of suspected ADR are: it may contain inappropriate clinical attributions of symptoms to specific medicines, the quality of patient report might be lower than reports made by HCPs, patient may misattribute symptoms to an ADR, higher proportions of non-serious ADRs may be reported, patient reporting might adversely affect their relationship with their prescribers, to analyse the patient reports it might be time consuming as they contain description of ADRs different from those of health professionals, possible duplication of reports and multiple reporting of same ADR. 6,7

\section{CONCLUSION}

Majority of ADRs were reported by HCP as compared to patient direct reporting of ADR. Comparison of ADR reporting between patient and HCP revealed that ADRs reported by patients were less in incidence, similar in qualitative analysis to $\mathrm{HCP}$ and had very elaborative narration and highlighted more about emotional, occupational and social impact due to ADR than HCP.

\section{Funding: No funding sources}

Conflict of interest: None declared

Ethical approval: The study was approved by the Institutional Ethics Committee

\section{REFERENCES}

1. Sriram S, Ghasemi A, Ramaswamy R, Devi M, Balasuramanian R, Ravi TK, Sabzghabaee AM. Prevalence of adverse drug reaction at a private tertiary care hospital in south India. JRMS. 2011;16(1):16-25.

2. Blenkinsopp A, Wilkie P, Routledge PA. Patient reporting of suspected adverse drug reactions: a review of published literature and international experience. Br J Clin Pharmacol. 2006;63(2):148-56.

3. Gonzalez EL, Herdeiro MT, Figueiras A. Determinants of under-reporting of adverse drug reactions: a systematic review. Drug safety. 2009;32(1):19-31.

4. Avery AJ, Anderson C, Bond CM, Gifford A, Hannarord PC. Evaluation of patient reporting of adverse drug reactions to the UK'Yellow Card Scheme': literature review, descriptive and qualitative analyses, and questionnaire surveys. Health Technol Assess. 2011;15(20):1-6.

5. Inman WHW. Attitudes to adverse drug-reaction reporting. Br J Clin Pharmacol. 1996;41:433-5.

6. Avery AJ, Anderson C, Bond CM, Fortnum $\mathrm{H}$, Gifford A, Hannaford PC, et al. Evaluation of patient reporting of adverse drug reactions to the UK' Yellow Card Scheme': literature review, descriptive and qualitative analyses, and questionnaire surveys. Health Technol Assess 2011;15(20):129.

7. Vijendra R, Pundarikaksha HP, Gopal MG, Girish K, Vasundara K, Jyothi R. A prospective study of cutaneous adverse drug reaction in a tertiary care hospital. National journal of basic medical sciences. 2013:3(1):44-51. 
8. Acharya T, Mehta D, Shah H, Dave J. Pharmacovigilance study of adverse cutaneous drug reactions in a tertiary care hospital. Nat $\mathbf{J}$ Physiol Pharm Pharmacol. 2013;3:75-81.

9. Arulmani R, Rajendran SD, Suresh B. Adverse drug reaction monitoring in a secondary care hospital in South India. Br J Clin Pharmacol. 2007;65(2):210-16.

10. Palanisamy S, Arul kumaran KSG, Rajasekaran A. A study on assessment, monitoring, documentation and reporting of adverse drug reactions at a multispeciality tertiary care teaching hospital in South India. International Journal of Pharm Tech Research. 1(4):1519-22.

11. Prosser TR, Kamysz PL. Multidisciplinary adverse drug reaction surveillance programme. Am J Hosp Pharm. 1990;47:1334-9.

12. Wester K, Jonnson AK, Spigset O, Druid H, Hagg S. Incidence of fatal adverse drug reactions: a population based study. $\mathrm{Br} \mathrm{J}$ Clin Pharmacol. 2007;65(4):573-79.

13. Gor AP, Desai SV. Adverse drug reactions (ADR) in the inpatients of medicine department of a rural tertiary care teaching hospital and influence of pharmacovigilance in reporting ADR. Indian $\mathbf{J}$ Pharmacol. 2008;40(1):37-40.

14. Vora MB, Trivedi HR, Shah BK, Tripathi CB. Adverse drug reaction in inpatient of internal medicine wards at a tertiary care hospital: a prospective cohort study. J Pharmacol Pharmacother. 2011;2(1):21-5.

15. Avery AJ, Anderson C, Bond CM, Gifford A, Hannarord PC et al. Evaluation of patient reporting of adverse drug reactions to the UK'Yellow Card Scheme': literature review, descriptive and qualitative analyses, and questionnaire surveys. Health Technol Assess. 2011;15(20):49-72.

Cite this article as: Ramakrishnaiah $\mathrm{H}$, Naidu $\mathrm{S}$, Jyothsnya S. A comparitive study of adverse drug reactions reported by healthcare professionals and patients in a tertiary care teaching hospital. Int $\mathbf{J}$ Basic Clin Pharmacol 2017;6:1078-84. 